ISSN: 0213-2052 - eISSN: 2530-4100

DOI: https://doi.org/10.14201/shha202139526

\title{
CIMERIOS, AMAZONAS Y EL ARTE GRIEGO
}

\section{Cimmerians, Amazons and Greek Art}

\author{
Arturo SÁNCHEZ SANZ \\ Universidad Complutense de Madrid* \\ asblade@msn.com
}

Fecha de recepción: 08-01-2021 Fecha de aceptación: 17-5-2021

ORCID: https://orcid.org/0000-0001-9642-5502

RESUMEN: En este artículo trataremos sobre las fuentes relativas al pueblo cimerio, su relación con los movimientos migratorios escitas a la región del Ponto septentrional y la relación de ambos pueblos con los mitos amazónicos. La influencia de las sociedades indoiranias en el arte heleno es bien conocida, aunque en muchas ocasiones se han ofrecido interpretaciones diversas a la aparición de arqueros orientales en numerosas piezas de pintura vascular. A continuación intentaremos explicar esas conexiones entre las sociedades nómadas orientales y los relatos míticos amazónicos en el periodo Arcaico, así como su interpretación en los motivos decorativos de la cerámica griega.

Palabras clave: Cimerios; amazonas; Mar Negro; escitas; mitología.

ABSTRACT: In this article we will explain the sources related to the Cimmerian people, their relationship with the Scythian migratory movements to the Northern Ponto region and the relationship of both peoples with the Amazonian myths. The influence of Indo-Iranian societies on Hellenistic art is well known, although diverse interpretations have been offered on many occasions of the appearance of Oriental archers in a lot of pieces of vascular painting. Below we will try to explain these connections between the eastern nomadic societies and the Amazonian mythical stories

* Investigador del Grupo ESCHATIA, Universidad Complutense de Madrid. «Delimitación territorial y fronteras. El papel de la religión en los conflictos entre poleis». 
in the Archaic period, as well as their interpretation in the decorative motifs of Greek ceramics.

Keywords: Cimmerians; amazons; Black Sea; scythians; mythology.

Tradicionalmente, la identificación del pueblo cimerio ha sido difícil, hasta el punto de ponerse en duda su existencia, en base a la posibilidad de que las fuentes estuvieran utilizando este término para referirse a los escitas. Ni siquiera podemos estar seguros de que se trate de un solo pueblo o varios grupos que, por las similitudes en cuanto a su modo de vida, apariencia, etc., fueron asociados por aquellos autores. Al mismo tiempo, la escasez de restos arqueológicos que podemos atribuirles (en la estepa septentrional, el norte del Cáucaso, la región Cárpato-Balcánica o en algunas ciudades que se asocian a sus campañas como Sardes, Éfeso, etc.) $)^{1}$ y su elevada dispersión podrían evidenciar una población reducida, aunque lo suficientemente importante para amenazar Urartu y saquear Asia Menor. Por si fuera poco, solo contamos con breves menciones, a cargo

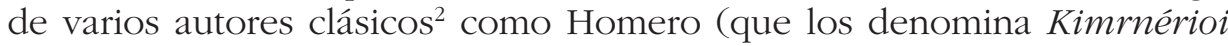
cuando relata el viaje de Odiseo al Hades al inicio del Canto X), así como fragmentos de alusiones en los textos asirios-babilonios (los llamados Gimri) ${ }^{3}$ y tres escasas citas en la Biblia ${ }^{4}$. Incluso, se les ha relacionado con el pueblo camarita, situado en la costa oriental del Ponto y mencionado por Estrabón, Tácito y Amiano ${ }^{5}$ o con los cimbros, que se cree que habitaron en torno al Bósforo Cimerio ${ }^{6}$ en los relatos de Estrabón ${ }^{7}$ o Diodoro ${ }^{8}$, por la similitud onomástica y a pesar de la distancia que separa a este pueblo germánico de la patria originaria cimeria.

Homero consideraba su organización social similar a la de los griegos, una apreciación que solo utiliza cuando se refiere a los troyanos, los feacios o los licios. Se trata de una alusión elogiosa a la par que idealizada? pues se basa en un conocimiento erróneo de su forma de vida. Homero

1. Ghirshman y Sonneville-David, Les Cimmériens, 55, lámina III, 2, 3, 5-6, IV, 3, VI, $1,2,3,7$.

2. Aristófanes Lis., 45; Pausanias 10, 9, 9. Hom. Od. 11. 14-19.

3. Según Diakonoff (The Cimmerians, 114-115) este término sería utilizado para definir a escitas o sakas.

4. A los que se denomina como Gomer o Gamadiens. Génesis 10. 2, 3 y Ezequiel 38. 6 у 27.11 .

5. Tácito An., 3. 47; Amiano Marcelino 22. 8, 24; Estrabón 11. 2, 12.

6. Plinio HN, 6. 6; Calímaco Himno a Artemis, 253-258.

7. Estrabón 7. 2, 2.

8. Diodoro 5. 32, 4 .

9. Ivantchik, Le dêmos, 87 . 
creía que se trataba de una sociedad sedentarizada que habitaba en ciudades; sin embargo, aunque es posible que se hubieran organizado en torno a algunos asentamientos de carácter permanente o semipermanente, olvida su carácter nómada destacado en la mayoría de fuentes posteriores. Como bien señalan Kirchhof ${ }^{10}$ y Wilamowitz ${ }^{11}$, probablemente los Cantos $\mathrm{X}$-XII de la Odisea se basaron en el relato argonáutico anterior.

Estos relatos, muchas veces relativos a leyendas que evocan lugares lejanos en el limes del mundo conocido, sitúan a los cimerios como parte de los «barbaros" extranjeros con los que los helenos alguna vez tuvieron contacto y que, por esa misma definición, se diferenciaban de su cultura. Algunas de dichas menciones les denominan "cerberios", una clara nomenclatura que los relaciona con Cerbero, el ser mítico que guardaba las puertas del Hades. No será hasta el relato de Heródoto ${ }^{12}$, que conoceremos más pistas acerca de este pueblo. Les hace habitar en los territorios que después quedarían en manos de los escitas (Escitia) y, por tanto, que estos controlaron hasta ese momento, al norte del Ponto (llamado Cimeria). Desconocemos con exactitud cuál era la amplitud real de sus dominios, pues solo se menciona con seguridad la actual península de Crimea, aunque pudo ser mucho mayor, desde el Don al noroeste del Cáucaso.

El relato de su expulsión tras la llegada de los nómadas escitas parece evidenciar tintes míticos, y el registro arqueológico no ha colaborado en demasía a la veracidad de este episodio, al margen de las alusiones epónimas $^{13}$. Incluso Posidonio señala que el Bósforo Cimerio no lleva ese nombre por la existencia de este pueblo, sino que se debe a la llegada a aquella región de los cimbrios desde occidente, que habrían sido conocidos por los griegos como cimerios $^{14}$, algo poco probable y que parece

10. Kirchhoff, Die Homerische Odyssee, 287-289.

11. Wilamowitz-Moellendorff, Homerische Untersuchungen, 165-167; Diellias, 361363 y $490-492$.

12. Heródoto 4. 11-13.

13. Sauter (Studiem zum, 142) niega este episodio indicando que no existen pruebas históricas de tal enfrentamiento, ni siquiera de sus consecuencias a través de numerosos kurganes que habrían tenido que ser erigidos para albergar a los cimerios caídos en combate frente a los escitas. En realidad, en este momento no es posible probarlo más allá de la especulación, pero inferir ello de la ausencia de pruebas podría poner en duda acontecimientos similares y que los investigadores no niegan como la misma expulsión de los escitas por los sármatas poco después. De este enfrentamiento directo tampoco contamos con pruebas específicas.

14. Poseid. en Strab. 7. 2, 2. Algo que defiende Pisani (Griechische Miszellen, 37). Pero como parece aceptable la explicación de Sauter (Studiem zum, 178), es posible que cuando los romanos llegaron a conocer las condiciones climáticas de la península de Jutlandia (que se hacía patria de los cimbrios), sus espesas nieblas, etc., pronto se asimilaron al entorno 
nacido de buscar una explicación basada en la similitud de sus denominaciones. Del mismo modo, Plutarco ${ }^{15}$ hace a los cimerios una tribu que formaba parte de los grupos celto-escitas, surgida en las regiones de contacto entre ambos grupos al norte del Ponto, aunque ello presupone una frontera entre celtas y escitas que difícilmente existió.

Los escitas pudieron decidir desplazarse tras sufrir la presión de otros pueblos en su territorio original oriental, como los masagetas ${ }^{16}$ (ubicados al norte y este del Mar Caspio, emparentados con los saka) o los isedones $^{17}$ (en Siberia y Asia Central), según Heródoto, o los arimaspos en la versión de Aristeas de Proconeso. No obstante, algunos de ellos, como los arimaspos (que parece que vestían y hablaban como los escitas) ${ }^{18} \mathrm{O}$ sus vecinos los hiperbóreos, eran pueblos ficticios ${ }^{19}$, y el resto de localización desconocida e identificación difícil. Sea como fuere, e independientemente de los motivos que llevaron allí a los escitas, es posible que no todos los cimerios abandonaran su territorio y, probablemente, muchos de ellos pasaron a ser asimilados por los recién $\operatorname{llegados}^{20}$. Se trata de un topos de las fuentes clásicas que se repetirá con el relato de la llegada de los sármatas mucho más tarde y que, como sabemos, tampoco supuso la extinción de los escitas en el s. IV a. C.

en que Homero describió el lugar de residencia de los cimerios al norte del Ponto. Incluso Hennig (Neue Betrachtungen, 292; Die westlichen, 5) y Duncan (Bede, Iona, 4) ya defendieron que ese panorama climático era muy similar al de las islas británicas, haciendo a los cimerios y escitas coincidir con grupos celtas situados en suroeste de Britania como los escotos (también por la similitud de sus denominaciones) y los pictos, basándose en el relato de Beda el Venerable (Historia Eclesiástica, 1. 1), opción que, al igual que Merrills (History and Geography, 284), creemos que es una invención propia. También en Italia, la alusión a la entrada al Hades que se asocia a la patria cimeria es utilizada por Plinio para situar a los cimerios en el asentamiento de Cumas, junto al lago Averno (Plin. HN. 3. 61). Los escotos fueron descritos por Isidoro de Sevilla por su afición a los tatuajes, al igual que sucede con los escitas. Isidoro (Orig. 9. 2, 103 y cf. 14. 23, 7).

15. Plut. Mar. 9. 6-8.

16. Estrabón 11. 6, 7, 8. Para Amiano (Historia, 31. 2, 12) masagetas y alanos eran el mismo pueblo.

17. Pueblo mencionado incluso por Alkman (F 192 C.).

18. En los que Parzinger (Die Skythen, 26) propone un origen mongoloide por la descripción de las fuentes, aunque la vestimenta escita y esa lengua era compartida por muchos pueblos esteparios.

19. De estos últimos así lo afirmaba el propio Heródoto (4. 36, 1).

20. Diakonoff (The Cimmerians, 124) incluso añade que los cimerios que protagonizaron la incursión en Asia Menor habrían sido varones que dejaron a sus mujeres en sus territorios al norte del Ponto, las cuales habrían sido asimiladas por los escitas tras su llegada. Historia que recuerda mucho al relato de Heródoto acerca del surgimiento del pueblo saurómata, en el que los escitas y un grupo de mujeres, esta vez amazonas, también estuvieron implicados. 
Se cree que se trataba de una tribu irania que alcanzó el norte del Ponto y Crimea en el s. VIII a. C., procedente de Asia Central ${ }^{21}$, más concretamente desde Kazajistán ${ }^{22}$. Mostraban un atuendo, armas y prácticas similares a los escitas y sakas, aunque también se piensa que descenderían de la cultura Srubna ${ }^{23}$ (llamada a veces cultura de las Tumbas de Madera), que se asentó entre el río Dniéper y el Volga durante los ss. XVI-IX a. C., y esta de las culturas previas Yamnaya y la cultura de las Catacumbas ${ }^{24}$. Una última opción la proporciona Lebedynsky, asociando una parte de su herencia a la cultura Sabatinovka que, a finales del Bronce, se asentaba entre el Danubio y el Dniéper ${ }^{25}$ y descendería de la cultura Bilozerka. El resto de su acerbo constituía una mezcla entre aportes de las culturas Kamychevakha-Tchornohorivka y Novotcherkassk al norte del Cáucaso, así como elementos procedentes de Siberia y Asia Central, que habrían sido los más importantes pues dos de los tres nombres de soberanos cimerios que han transmitido las fuentes tienen una raíz semántica irania.

No podemos estar seguros pero, tras atravesar el Cáucaso, los autores clásicos afirman que ocuparon varios enclaves en Asia Menor, antes de su desaparición definitiva. Ivantchik o Ustinova ni siquiera les conceden entidad propia, incluyéndolos dentro del horizonte material denominado escita arcaico ${ }^{26}$, en base a que sus características socio-culturales y económicas están ligadas a los grupos nómadas de Eurasia. Se ha argumentado la existencia de dos culturas preescitas y autóctonas, denominadas Chemogorovsk y Novocherkassk, en base a la similitud de su registro funerario y cerámico. Estas se habrían desarrollado en la estepa septentrional del Ponto entre los ss. IX-VII a. C., desarrollándose hasta configurar los pueblos escitas y cimerios, lo que dificultaría también diferenciar el registro material de ambos grupos en aquella región por su origen común ${ }^{27}$. Sin embargo, Jacobson defiende la procedencia oriental de los escitas ${ }^{28}$ y Prusek asegura que los cimerios aparecieron en la región de Transcaucasia y

21. Lebedynsky, De L'epee scythe, 20.

22. Harmatta, Studies on the history, 37.

23. Igual que los escitas según Diakonoff (The Cimmerians, 123).

24. Mongait, Archaeology in the U.S.S.R., 155.

25. Lebedynsky, Les Cimmériens, 70.

26. Ivantchik, Sinope et les, 66; Ustinova, The supreme gods, 13.

27. Jacobson, The art of the, 36 .

28. Incluso señala (The art of the, 27-28) que los relieves de Persépolis, donde aparecen representados escitas, medos y sogdianos con vestimentas similares, podrían reflejar un pasado común centroasiático. 
las regiones orientales de Asia Menor $^{29}$ en torno al s. VIII a. C. Otros como Lebedynsky señalan que su territorio habría estado enmarcado desde el oeste de la desembocadura del Danubio o el curso del Dniester (donde se cree que podría localizarse la necrópolis real cimeria) ${ }^{30}$ y el este con el Don.

No parece que podamos descartar fácilmente su importancia y entidad cultural toda vez que, si bien es cierto que los restos de su paso por la costa sur del Ponto son extremadamente escasos, puede deberse a la necesidad de ampliar unos estudios arqueológicos que, en aquella región, aún son limitados, y no ocurre lo mismo en la costa del Próximo Oriente, donde su rastro material es más abundante. Estos reducidos datos solo nos animan a pensar que se trató de un pueblo nómada emparentado con los escitas (probablemente también de origen iranio), que alcanzó aquella región alrededor del s. VIII a. C. desde el este (quizá la región centro-septentrional de Asia Central) y se asentó en un territorio de fronteras indeterminadas en la estepa póntica (incluyendo Crimea).

Sin embargo, sabemos por Estrabón que, tras la llegada de los escitas poco después, se vieron obligados a una nueva migración bordeando la costa norte del Ponto, y cruzaron el Cáucaso (documentos asirios ${ }^{31}$ la sitúan a finales del s. VIII a. C., los cuales mencionan a los escitas por primera vez ${ }^{32}$ en el 681 a. C.). Se asentarían brevemente al sur de esta cordillera $^{33}$, donde protagonizaron varios enfrentamientos con urartios y asirios (las crónicas babilonias sitúan este último acontecimiento en torno al 678 a. C.), antes de dirigirse al sur del Ponto y alcanzar la península en que se ubicaba la reciente colonia milesia de Sinope ${ }^{34}$. Sin embargo, Orosio ${ }^{35}$ señala, de manera difícil de encajar con el resto de menciones, que este acontecimiento no solo se habría producido mucho antes (ca. 786-783 a. C.), sino que los cimerios lo habrían llevado a cabo en colaboración con las

29. Prusek, Chinese statelets, 119.

30. Lebedynsky, Les Cimmériens, 95.

31. Waterman, Royal Correspondence, 75-77; Latyshev, Izvestiya drevnikh, 14-17.

32. Latyshev (Izvestiya drevnikh, 18-19) y Porada (The Art of Ancient, 123) lo utilizan para indicar la posibilidad de que cimerios y escitas sean denominaciones de un mismo grupo, aunque no necesariamente, pues es posible que una fuente mencione a grupos contemporáneos en momentos y lugares similares por diversos motivos. Los cimerios dejaron de mencionarse en las fuentes tras su derrota frente a Aliates II en el tercer cuarto del s. VII a. C., mientras que los escitas mantuvieron sus referencias recurrentes muchos siglos después.

33. Al norte, noroeste o noreste del país de Urartu para Kristensen (Who were the, 13-14), aunque Salvini (Geschichte und, 87) llega más lejos, a la meseta irania.

34. Heródoto 4. 12.

35. Oros. Hist., 1 21,1.2. 
amazonas (el mítico pueblo de guerreras cuya patria se sitúa tradicionalmente en el Termodonte).

El nombre de esta ciudad es asociado a una amazona en el periplo de Pseudo-Escimno ${ }^{36}$, pues no olvidemos que se encontraba muy cerca, al oeste del Termodonte, quien indica que, previamente, se asentaba un pueblo al que denominaba Syroi. Probablemente, y en realidad, los cimerios habrían ocupado una ciudad previa y perteneciente a ese pueblo para abandonarla poco después ${ }^{37}$, siendo reconstruida por los colonos milesios $^{38}$. A tan solo $130 \mathrm{~km}$ al sur de Sinope, en la villa de Imirler (cerca de Merzifon) se ha localizado la tumba de un guerrero escita ${ }^{39}$ junto a su caballo y armas. Su periplo continuó hacia el sur, atacando el reino de Frigia, en Asia Menor, donde acabaron con la vida de su rey ${ }^{40}$, acontecimiento que pudo suceder en el primer cuarto del s. VII a. C. ${ }^{41}$. Poco después harían lo propio con Paflagonia, Bitinia, Lidia y Jonia, destruyendo importantes ciudades como Sardes ${ }^{42}$ o Éfeso ${ }^{43}$ antes de desaparecer de los registros.

Eran descritos como grupos de nómadas guerreros a caballo que, a veces, incluso se les ha asociado a otra tribu de origen tracio, los treres ${ }^{44}$. No obstante, según Estrabón, estos habrían ocupado Sardes después que los cimerios y antes que los licios ${ }^{45}$. Diakonoff señala el error de Estrabón al confundir ambos pueblos ${ }^{46}$, y así es, aunque no sería descabellado pensar que en algún momento una tribu tracia cruzara el Bósforo y atacara Sardes pues, aunque desconocemos el territorio original que ocuparon los treres, desde el corazón de Tracia hasta allí la distancia es mucho menor que aquella que cubrieron los cimerios desde el Cáucaso.

36. Ps. Scymn. 986-997 Diller = F 27 Marcotte = Anon. Peripl. Pont. Eux., 22, 8v35-38. El cual no podemos considerar como una periégesis (Rostowzew, Skythien und der, 27). Todos los nombres de amazonas que conocemos muestran un claro origen griego o variantes feminizadas de los nombres de los reyes escitas (como Escileia del rey Esciles, Bothmer, Amazons in Greek, pl. 19).

37. Heródoto menciona que permanecieron allí un largo tiempo, pero el registro arqueológico lo desmiente. Ivantchik, Sinope et les, 66.

38. Como se desprende de un fragmento de Flegón de Trales recogido por Esteban de Bizancio (FGrHist 257 F 30).

39. Unal, Zwei Graber, 65-81.

40. Estrabón 1. 3, 21.

41. Lebedynsky, Les Cimmériens, 17.

42. Heródoto 1. 15.

43. Calímaco, Himno a Artemis, 251-258.

44. Tucídides 2. 96; Estrabón 1. 3, 18; Esteban de Bizancio 97. 16-21.

45. Estrabón 13. 4, 8.

46. Diakonoff, The Cimmerians, 104. 
Su última mención los hace ser derrotados por el rey licio Aliates quien, en el s. VI a. C., los expulsaría de Asia Menor y nunca más fueron mencionados, lo que podría implicar su desaparición. Sabemos que Arriano trató sobre los cimerios en su Historia de Bitinia, donde los consideraba emparentados con los escitas ${ }^{47}$. Señala que llegaron a Asia Menor tras abandonar su patria, desapareciendo de la historia tras ser derrotados por los bitinios cuando alcanzaron aquella región. En realidad, Arriano no indica que fueran los bitinios quienes les expulsaran, pues denomina a sus enemigos como tracios, y muchos autores lo han asociado a los bitinios que, a veces, recibían el nombre de "tracios del este». Sin embargo, siguiendo con nuestra disposición a no descartar opciones tan a la ligera, aunque esta solución pueda ser más que correcta, tampoco podríamos negar que, tras su conquista de Bitinia, quizá un grupo de tracios, posiblemente los treres, en una campaña de saqueo al otro lado del Bósforo se encontraran con ellos, los derrotaran y después ellos mismos ocuparan Sardes. Una secuencia de acontecimientos que cuadra con el orden de los pueblos que atacaron la ciudad en aquella época, ofrecido por Estrabón, y que de ese modo explicaría que aparezcan ligados a los cimerios en las fuentes.

No obstante, las fechas que manejamos son difíciles de articular hasta lograr un relato verosímil. La llegada de los cimerios a Asia Menor está documentada a principios del s. VII a. C., justo en el mismo momento en que se cree que los escitas habrían alcanzado su territorio al norte del Ponto. Como bien señala Lebedynsky ${ }^{48}$, es difícil pensar que ambos acontecimientos estén asociados, aun cuando las fuentes indican que los escitas alcanzaron Asia Menor en persecución de aquellos. Un acto asî requeriría pensar en que los escitas tenían algún motivo personal para dedicar tiempo y esfuerzo en acabar con un pueblo al cual ya habían arrebatado su territorio, es más, indicaría que ese conflicto, y su aparición en Asia Menor, se dieron en un margen de tiempo muy reducido.

Por otro lado, no tenemos noticias de que, tras cruzar el Cáucaso, los escitas siguieran hostigando a los cimerios mientras estos atacaban los reinos anatolios. Aun más, sabiendo que sus enemigos venían por el este, la solución más viable para escapar habría sido el oeste, hacia el territorio tracio, pero decidieron bordear el Ponto hacia el Cáucaso, solo un poco más al sur de la región por la que estaban penetrando los escitas y siendo atacados. La posibilidad de Lebedynsky acerca de que los cimerios sí que huyeron hacia el oeste bordeando el Ponto hasta acceder a Asia Menor tras cruzar el Bósforo se antoja también complicada, pues sabemos que

47. Eustath. ad Horn. Od. XIII, 14sqq. 1631, 27.

48. Lebedynsky, Les Cimmériens, 21-22. 
atacaron primero Paflagonia y la región del Ponto antes de dirigirse hacia Frigia, Lidia y luego a Jonia. Una ruta extraña cuando ya se encontraban al norte de Jonia desde su llegada. Si bien es cierto que dicha ruta permite alcanzar Asia Menor desde el norte del Ponto más rápidamente, así como pudo permitirles retirarse lejos de los escitas y no siguiendo una ruta que pasaba muy cerca del territorio por el que estos estaban penetrando hacia el suyo desde el este, no podemos descartar que la elección de ese recorrido respondiera a la existencia de buenas relaciones con los pueblos del Cáucaso, que habrían permitido su paso sin oposición, algo que pudiera no haber sido tan sencillo en territorio tracio.

Diakonoff ${ }^{49}$ explica la ruta del Cáucaso indicando que, tras sus enfrentamientos con los urartios ${ }^{50}$, una alianza de estos con los frigios habría conseguido expulsarles de aquella región hacia el oeste y, tratando estos nómadas de evitar enfrentarse a los propios frigios en sus dominios, se encaminaron primero hacia Paflagonia. No sabemos si pudo producirse de ese modo, aunque parece difícil que los frigios ayudaran a los urartios sin motivo aparente y con la amenaza de que expulsarlos del sur del Cáucaso podría acercar el problema a su propia frontera cuando aún estaba lejos. Otros autores sostienen que los urartios se habrían aliado con escitas y cimerios para acabar con los asirios ${ }^{51}$.

Queda claro que si los cimerios nunca hubieran llegado al sur del Cáucaso sería difícil que hubieran sido alguna vez conocidos y mencionados por los asirios, como así sucede ${ }^{52}$, ubicándolos cerca del reino de Urartu

49. Diakonoff, The Cimmerians, 109.

50. Se han localizado decenas de puntas de flecha escitas, empleadas también por los cimerios, en los muros de la fortaleza urartia de Ayanis Kaie, situada cerca de la capital urartia y datadas en el tercer cuarto del s. VII a. C. (Burney, A First Season, 79; Ivantchik, La légende, 331). El descubrimiento de restos arqueológicos estrictamente cimerios es complicado en la estepa euroasiática y en los lugares donde más tarde se asentarían los escitas, pues al tratarse ambas de culturas nómadas de características muy similares es difícil asignar dichos restos con seguridad, por ello es importante datar los restos nómadas existentes en Asia Menor desde el s. VII a. C. en adelante pues sabemos que en esa fecha solo los cimerios habían alcanzado aún aquella región y pueden asignarse menos controvertidamente. Encinas Moral (Etnogénesis y evolución, 362-363) y Grákov (Die Skythen, 30) indican que las puntas de flecha pudieron haber servido como moneda de cambio empleada por los escitas, los tracios y los olbitas.

51. Azarpay, Urartian art, 61; Piotrovskiy, Vanskoye tsarstvo, 112-114. Sabemos que en numerosos enterramientos masculinos y femeninos asociados a los urartios y fechados en el s. VIII a. C. se ha localizado un tipo de arma específico consistente en un cuchillo de hierro de hoja curva. Ello podría reflejar ciertas similitudes con las tumbas femeninas escitas, sármatas, etc., y propiciar una alianza (Mohen y Ėrmitazh, Avant les Scythes, 207).

52. En aquella región se han localizado los restos materiales cimerios más antiguos. Para Harmatta (Studies on the history, 36) parte del pueblo cimerio habría emigrado desde 
(Armenia). El propio Heródoto señala que los escitas debieron cruzar el rio Araxes para llegar a Cimeria. Si estos se cree que llegaron al norte del Ponto desde el este del Volga, no habrían necesitado nunca cruzar este río, que fluye en el Cáucaso, para acceder allí, solo hubiera sido obligado si desde el norte del Caspio tornaron al sur para cruzar el Cáucaso. Del mismo modo, esta ubicación permitiría entender mejor por qué los cimerios se dirigieron hacia Asia Menor al ser expulsados, ya que esa región estaba relativamente cerca y tendrían un conocimiento suficiente, tanto de ella como de sus reinos y riquezas, como para intentar explotarlos, que si vivieran al otro lado del Ponto y sin una tradición marinera o comercial que desde allí les reportara un conocimiento similar.

Así, los escitas no habrían llegado para expulsarles sino quizá para saquear su territorio, abandonándolo después hacia su asentamiento definitivo en la estepa occidental de Eurasia, y los asirios habrían tenido un claro conocimiento de los cimerios al estar su territorio muy cerca. El único problema que presenta esta teoría es de carácter toponímico, pues, si los cimerios nunca hubieran estado presentes en Crimea, no se explica fácilmente que el estrecho de Kerch sea denominado tradicionalmente Bósforo Cimerio ${ }^{53}$, o que una de las colonias griegas fundadas al suroeste de Panticapea en el s. VI a. C. se denominara Cimerikón ${ }^{54}$.

Tampoco parece que podamos achacarlo a una denominación generada por los colonos griegos ${ }^{55}$ ya que, teniendo en cuenta que, si bien los cimerios ya no existían en el territorio en el que se erigieron las colonias griegas del norte del Ponto, los griegos podrían haber empleado cualquier otro topónimo para designar al estrecho de Kerch, por lo que su perpetuación implicaría una existencia anterior de tal denominación que fue mantenida, y que solo podría señalar una presencia cimeria previa en esa región. Del mismo modo, se han localizado restos del paso de los cimerios por Asia Menor, pero desconocemos desde dónde habrían llegado hasta alcanzar el sur del Cáucaso, algo que se ha resuelto haciéndolos autóctonos de aquella región. Sin embargo, no es difícil pensar en una posibilidad aglutinadora.

Quizá los cimerios se hubieran asentado al norte del Ponto entre el IX-VIII a. C., iniciando una parte de ellos el periplo en dirección a Asia Menor a través del Cáucaso antes de la llegada de los escitas (principios

allí hacia el norte del Ponto en el s. VIII a. C., lo que les convertiría en los primeros nómadas iranios que alcanzaron el occidente de Eurasia.

53. Heródoto 4. 12.

54. Gaydukevich y Kaposhina, K voprosu, 165; Ustinova, The supreme gods, 3

55. Diakonoff, The Cimmerians, 125 . 
del s. VII a. C.), quienes habrían asimilado a los rezagados. Se habrían asentado al sur de aquella cordillera, donde serían conocidos por los asirios de Asurbanipal para, poco después, iniciar esas campañas ${ }^{56}$ y nueva migración hacia Asia Menor. De ese modo, la aparición de los escitas en aquella región quizá no estuvo relacionada con ellos, aunque se produjera en un momento cercano, desapareciendo tras esos acontecimientos de las fuentes, pero quedando esas alusiones a su existencia.

Otra discrepancia interesante con las fuentes clásicas es su consideración de pueblo nómada. Homero fue el primero que los menciona viviendo en ciudades $^{57}$, y sabemos que en su campaña en Asia Menor habitaron temporalmente en varias de las que lograron conquistar. El propio Aristóteles ${ }^{58}$ defendía que habitaron en ciudades durante mucho tiempo. No obstante, la mayoría de los autores descartan convertirlos en un pueblo sedentario y la mención de Homero podría ser considerada como mítica, pues tampoco se han descubierto restos arqueológicos de estas o se trataba de asentamientos temporales que no han dejado evidencias. A pesar de ello, su modo de vida, lucha y tácticas militares se muestran claramente asociados a los jinetes nómadas de las estepas, lo que no descartaría que pudieran residir, temporalmente, en las ciudades que conquistaron o en asentamientos de carácter temporal.

Sobre ello, Ghirshman relaciona el mito amazónico con los cimerios, al considerar que sus mujeres habrían participado en las campañas bélicas como parte de la tradición nómada que equipara a ambos sexos a nivel social y que tras su llegada al norte del Ponto habrían ayudado a la creación del mito ${ }^{59}$. Incluso, va más allá. Su extensa teoría que une los destinos de cimerios y amazonas hace converger el origen de los primeros y los escitas, señalando que fueron estos últimos los que atrajeron a los escitas hacia Asia Menor y no al contrario.

Los escitas habrían emigrado hacia el sur del Cáucaso y los cimerios al norte del Ponto, desde donde se desplazaron poco después hacia Capadocia. La fecha de este evento la sitúa mucho antes de finales del s. VII a. C., en que los cimerios son mencionados por primera vez por las fuentes asirias, hipótesis inferida en cuanto a que si su nuevo territorio ya era conocido entonces como Guriania, debió haberse formado mucho antes.

56. Lebedynsky (Les Cimmériens, 29) indican que ello pudo darse como resultado de un ataque de los urartios cuyo territorio desprotegido habría tratado de ocupar el soberano asirio Asarhadon, terminando por enfrentarse a los cimerios, aunque no contamos con pruebas de ello.

57. Hom. Od., 11. 14

58. Citado por Esteban de Bizancio 97. 16-21.

59. Ghirshman y Sonneville-David, Les Cimmériens, 12. 
Hasta este punto el relato, aunque novedoso, no es del todo impensable, salvo las pruebas existentes de que los escitas habitaron al norte del Ponto en esas fechas y la contradicción que supone a lo expresado por Heródoto, pues el resto siempre se ha basado en hipótesis asentadas en muy pocos datos que permiten diversas opciones.

En este momento, ahora sí teniendo en cuenta a Heródoto, asume que su mención a la fundación de Sinope se refiere a los cimerios ${ }^{60}$, y une esta tradición a aquellas que relacionan la ciudad con las amazonas para unir ambos pueblos en uno solo ${ }^{61}$. Para ofrecer más similitudes, indica que las amazonas hablaban la lengua escita, que era la misma que la cimeria, aunque, nuevamente, se olvida del relato de Heródoto acerca de la creación del pueblo saurómata, donde los escitas no entendían el lenguaje de las amazonas y estas tuvieron que aprender el de aquellos ${ }^{62}$; mientras que sî recuerda este pasaje para indicar que, al igual que las amazonas lucharon con sus maridos una vez crearon el pueblo saurómata, lo mismo hicieron las amazonas y sus maridos cimerios. Así, Temiscira no habría sido solo la capital amazónica, sino la metrópoli cimeria desde la cual fundaron Sinope y realizaron el resto de expediciones por toda Asia Menor (ciudad de la cual no existen pruebas ni restos arqueológicos).

Una vez equiparados cimerios y amazonas la situación se complica aún más, y no solo por el hecho de que las amazonas son un pueblo mítico. Entiende que el pasaje de Homero en que relata la lucha entre un joven Príamo (más tarde soberano troyano) y las amazonas sería una prueba irrefutable de que los cimerios ya se encontraban en Asia Menor en el último tercio del II milenio a. C., más de medio siglo antes de la fecha que entendemos más precisa. No obstante, señala que el reino frigio se habría formado entre el 1000-800 a. C., por lo que, en realidad, la llegada de los cimerios a Asia Menor no habría sido posible mucho antes, aunque la guerra de Troya se produjo más de un cuarto de siglo antes del margen superior de esa fecha. Emplea también el relato de Príamo para establecer una existencia de los cimerios anterior a las fuentes asirias, no es fácil desdeñar después la fecha estimada para la guerra entre aqueos y troyanos si aparenta ser demasiado antigua.

De este modo, su empleo de fuentes como Estrabón o Trogo, aprovechando la confusión de sus relatos a la hora de tratar a las tribus nómadas

60. Heródoto 4. 12.

61. Ghirshman y Sonneville-David, Les Cimmériens, 38-39.

62. Sin embargo, Ivantchik (La légende, 213) señala la existencia de varios dialectos escitas muy diferentes entre sí, lo que podría favorecer esa incomprensión entre grupos escíticos, aunque quizá nunca totalmente como sucedía entre escitas y amazonas. 
de Asia, así como el uso sesgado de otras fuentes y de lo que poco que en este tema nos ha aportado el registro arqueológico (difícil de asociar a los cimerios inequívocamente frente al registro escita en el norte del Ponto y por ello omitido aquí), articulan una hipótesis imposible de defender. Ello demuestra el sumo cuidado que debemos tener a la hora de ahondar en las fuentes, de comparar la información que aportan con el registro arqueológico y, a la vez, lidiar con la multitud de textos que tan extendido mito han generado en la literatura contemporánea.

No todas las sociedades nómadas mostraron tal consideración, menos aún aquellas que se articulaban mediante una economía agropastoril. A pesar de que, en este caso, varias de las sociedades nómadas del Ponto mantuvieron esta característica, no tenemos datos suficientes para asociarla también a los cimerios pues apenas se han descubierto restos de su cultura. Del mismo modo, contamos con referencias escritas y arqueológicas a ello entre los escitas, sármatas, sakas, tagar, etc., pero no así con los cimerios. Orosio o Eusebio de Cesarea los asocian, con base en la teoría cronológica, al ser mencionados cimerios y amazonas como actores en la guerra de Troya.

Sin embargo, el propio Homero no menciona esa participación y, aunque pudiera entenderse como tal, la fecha histórica de dicho suceso habría sido muy anterior a la llegada de los cimerios al norte del Ponto, lo que solo podría explicarse por los problemas que supone asociar acontecimientos históricos a una fecha concreta dentro del imaginario griego, que entendía su pasado mítico muy anterior a los hechos reales. En cualquier caso, Homero escribió en la época en que los cimerios vivían al norte del Ponto y poco después se desplazaron a Asia Menor. Curiosamente, gran parte de las fuentes que mencionan los mitos amazónicos sitúan allí su reino, y ello puede ayudar a asociar ambos pueblos que entendían que compartían ciertas características, aunque la mayoría apuesta por el Termodonte y otros lugares como el Cáucaso, Hircania, etc.

No dudamos de que, entre los cimerios, las mujeres pudieran participar en campañas militares, y que su visión, por parte de los griegos jonios, eolios, etc., ayudara a asociarlos, pero el mito amazónico se creó mucho antes de la aparición de los cimerios en el Ponto septentrional. Desconocemos el momento exacto, pero sí con la suficiente antelación al s. VIII a. C., en que escribió Homero, como para que las amazonas fueran reconocidas en el imaginario griego por toda la población, pues nuestro poeta no necesitó más explicaciones para su público. Probablemente el mito amazónico ya existía tiempo atrás. Cuando los griegos conocieron a 
los cimerios $^{63}$, y posteriormente a escitas (mitos que los relacionan con la campaña de Atenas) y sármatas (el origen de los saurómatas), comenzaron a asociarlos con base en esa condición de la mujer guerrera en estos pueblos nómadas y su ubicación en territorios antes asociados al reino amazónico.

En cuanto al material arqueológico propiamente cimerio, ya hemos mencionado que solo se han localizado unos pocos kurganes y muy dispersos, quizá debido a que muchos de sus restos han sido identificados erróneamente como escitas o sakas ${ }^{64}$. En cuanto al armamento destacan los $\operatorname{arcos}^{65}$ y las flechas (muy similares a los que emplearon aquellos) y solo se ha localizado una tumba individual femenina que contaba como ajuar con un punzón y una aguja de hierro (Tumba 2 del Kurgán de Tchornohorivka ${ }^{66}$. No parece, pues, que el estatus femenino alcanzara el mismo grado que veremos más tarde en el ámbito escita, sármata o saka. Sin embargo, no podemos olvidar que, aunque en un porcentaje muy elevado de tumbas femeninas en estas culturas se localizaron armas y que ello podría asociarse al mito amazónico, en otras muchas no sucedía así. Aunque analizaremos ello más adelante, se hace complicado descartar totalmente tal posibilidad en el mundo cimerio, con tan pocos elementos descubiertos.

Existen muy pocos elementos iconográficos en el mundo griego que representen, inequívocamente, a los cimerios. Tanto es así, que solo conocemos uno, el vaso François (Fig. 1), ya que otras escenas, como la del sarcófago de Clazomene, pueden representar tanto a cimerios como a escitas y, por tanto, no son fiables. En este caso, la pieza está fechada entre el 570-560 a. C., y representa la caza del jabalí de Calidón, donde uno de los protagonistas es nombrado Kimepioe y aparece provisto de un arco. Está claro que aquí el nombre atribuido al pueblo ha sido usado como un antropónimo, similar a lo que ocurre con otro de los arqueros, nombrado Toxamis, que es un apelativo conocido para el mundo amazónico ${ }^{67}$, de forma que el autor ya muestra esa asociación de los cimerios con las amazonas mucho antes que Heródoto.

63. Incluso los clásicos asocian a las amazonas con la fundación de Sinope, una ciudad que sabemos que fue conquistada por los cimerios en su periplo en Asia Menor. Heródoto (4. 12), Pseudo-Scymnès (5. 948) y Hecateo (Frg. 352) argumentan que estuvieron acompañados por los tracios.

64. Diakonoff, The Cimmerians, 133 .

65. Harmatta, Studies on, 37.

66. Lebedynsky, Les Cimmériens, 78.

67. Dos vasos áticos muestran inscripciones alusivas al nombre de las amazonas que representan: Toxis y Toxaris (Bothmer, Amazons, pl. IX 5 y 7). Curiosamente, esta segunda 


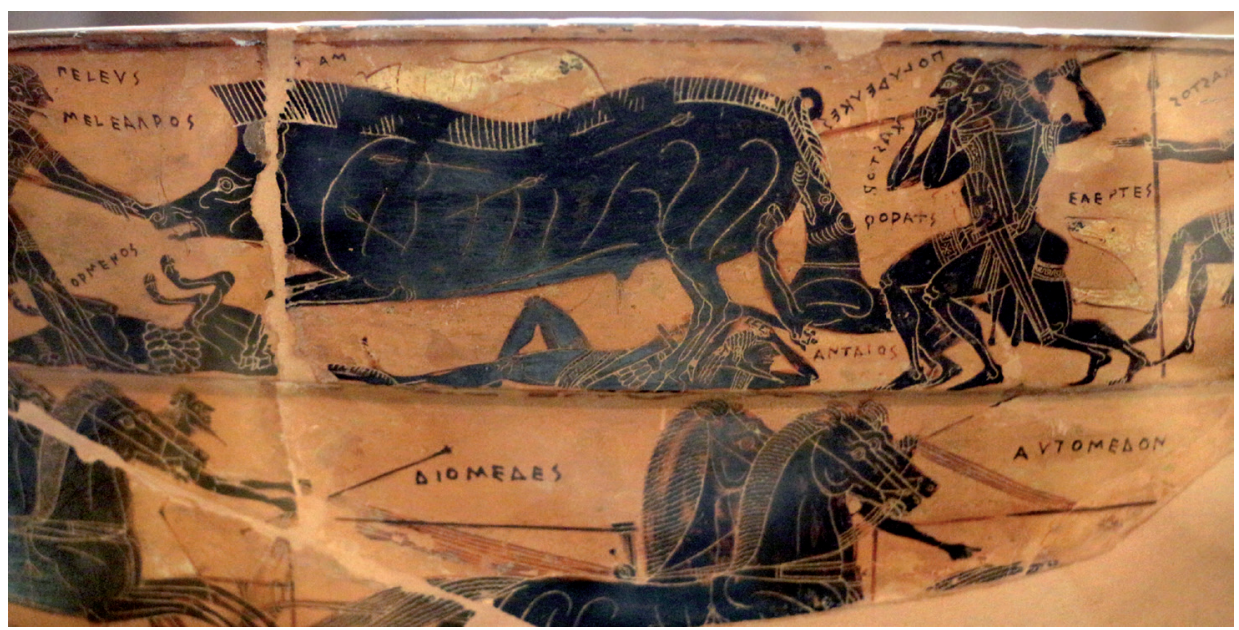

Fig. 1. Vaso François. Florence, National Museum of Archaeology.

En este sentido, hemos de mencionar la compilación más importante que se ha realizado hasta la fecha en cuanto a representaciones de arqueros escitas en vasos áticos, obra de Lissarrague, aunque circunscrita únicamente al Periodo Arcaico. Este ha localizado cerca de 700 piezas, de las que solo 80 muestran arqueros desnudos u hoplitas con $\operatorname{arco}^{68}$ (que quizá no estarían mostrando personajes escitas, en mi opinión, lo que rebajaría esa cifra a las 620, y aproximadamente 30 de estas pertenecen a una época entre el 480-470 a. C., que, si entendemos como ya perteneciente al Periodo Clásico, la reduciría aún más hasta las 590, con solo 30 de ellas en esta época posterior).

Al margen de la posible relación que los griegos establecieron a nivel mítico entre las amazonas y los escitas, las representaciones que hemos compilado en nuestro propio catálogo de amazonas en vasos áticos desde finales del s. VII a. C. a finales del s. IV a. C. arrojan una cifra muy superior $\left(3.448\right.$ piezas) ${ }^{69}$, lo que implicaría un mayor interés de los artistas áticos por este tema (si bien es cierto que alude a toda la Antigüedad, pero 1.457 pertenecen exclusivamente al Periodo Arcaico, además de otras 687, que podrían incluirse al ser datadas entre el 525-475 a. C., probablemente las escenas de escitas de la Época Clásica no alcanzarían para superar esta

opción sería empleada por Luciano de Samosata en el s. II d. C. para titular uno de sus diálogos llamado Tóxaris, entre un griego y un escita llamado así (aquí nombre masculino).

68. Lissarrague, L'autre guerrier, 247-293.

69. Sánchez Sanz, Ars Amazonica, 19. 
cifra). Lo que no cabe duda es acerca de la relación entre las representaciones de figuras con vestimenta escita y el uso del arco, pues en el estudio de Lissarrague alcanzan el 88,6 \%, lo mismo que sucede en el caso amazónico, donde el porcentaje es muy elevado.

Es interesante la teoría de Ivantchik, para quien las representaciones de arqueros escitas (con sus gorros y vestimenta característicamente asociados) en los vasos griegos no se referían a personajes reales, ni los artistas buscaron referir un episodio concreto. Defiende que su atuendo mostraba el convencionalismo iconográfico del arquero $^{70}$, relacionado con el papel subordinado de estas figuras con respecto a los hoplitas griegos que se muestran en ellas ${ }^{71}$, mostrando más su función que su procedencia y solo aplicable a aquellas obras elaboradas entre el 530-490 a. C. Tras el enfrentamiento con los persas dicha vestimenta escita habría pasado a ser entendida, ahora sí, étnicamente, aunque no con respecto a los escitas sino a los persas, de manera que, para nuestro autor, ninguna representación iconográfica de un personaje con atuendo escita se refirió a la propia etnia escita. Se trata, esta, de una visión similar a la que se ha expresado acerca del papel subordinado de las mujeres que visten, despiden, etc., a los guerreros en otras escenas. No obstante, no podemos por menos que recordar aquí las representaciones de escitas individuales, las cuales requerirían de otro tipo de explicación.

Del mismo modo que, aplicado a las amazonas, muchos autores han estimado una visión similar al indicar que, tras dicho enfrentamiento, el cambio en la representación de la vestimenta amazónica hacia este tipo de elementos las equipararía a los persas (como enemigas que eran igual que aquellos) y no a los escitas ${ }^{72}$. Sin embargo, aunque dicha teoría es posible, los escitas no fueron siempre enemigos de los griegos, ni antes ni después de las Guerras Médicas. Incluso actuaron como mercenarios para los griegos en ambos periodos y se les conocía por esa actitud tradicionalmente. ¿Por qué representar a las amazonas como un contingente escita cuando sabían que su participación en las Guerras Médicas al lado de los persas pudo ser obligada o comprada? ¿Por qué no representarlas con el atuendo medo o persa en lugar del escita? Las amazonas nunca actuaron como mercenarias en su universo mítico, del mismo modo que ningún Estado o polis guardaba rencor a la patria de los mercenarios a los que se enfrentaron, pues su función no implicaba animadversión, sino que se trataba de un oficio reconocido y del que los propios griegos hicieron uso

70. Ivanchik, Le dêmos et, 102.

71. Ibíd., 197.

72. Mayor, The Amazons, 37-38. 
extenso. Se trata, por tanto, de preguntas difíciles de responder con total seguridad.

En este sentido, Skrzhinskaya y Blok ${ }^{73}$ sostienen que las representaciones de escitas se engloban siempre dentro del ámbito mítico griego, con la excepción del Periodo Arcaico en que también aparecerían como personajes dramáticos. No obstante, veremos que existen representaciones donde los escitas se muestran luchando con hoplitas griegos innominados sin que conozcamos relato alguno donde ello se indique. Incluso, en el mito de Teseo y Antíope, la versión que hace a los escitas ayudar a las amazonas indica que estos no llegaron a enfrentarse a los griegos, por lo que solo podrían aludir a enfrentamientos en los que estos actuaron como mercenarios para los enemigos de los helenos, y que se les represente solo a ellos es significativo para dudar de tal posibilidad.

La última opción es que, como indica Ivantchik, dichos combates formaran parte de mitos que nos han llegado, pero, igualmente, es difícil que, si entendiéramos así estas representaciones, una simbología que debió ser conocida por el conjunto de los griegos para ser entendida sin más detalles en esas representaciones debió haber dejado algún rastro en las fuentes clásicas. Mitos poco conocidos o locales existieron, algunos con versiones muy personales, pero es difícil entender que se representaran en vasos para la exportación y se esperara que su significado fuera conocido allí donde se enviaran, a no ser que su utilización se hiciera solo con fines decorativos, lo que cambiaría el sentido de estas escenas.

\section{Conclusión}

Más interesante, a mi parecer, es la opinión de Braund, Frolov y Alekseev, para quienes dichas representaciones escíticas buscaban aludir a la relación entre estos y los griegos ${ }^{74}$. Quizá no se trataba tanto de escenificar acontecimientos concretos, sino de mostrar personajes en acciones reconocibles y genéricas. En ellas, la elección de los escitas para actuar en el papel de actores secundarios habría estado relacionada, precisamente, con su atuendo. Este era tan diferente al del hoplita que no permitiría dudas acerca de su condición ni haría sombra al engrandecimiento del héroe griego. Sin embargo, elementos distintos y reconocibles de la panoplia militar griega habrían permitido a los artistas emplear otras figuras

73. Skrzhinskaya, Geroi kimmeriiskikh, 84-94; Blok, The Early Amazons, 413-414.

74. Braund, Scythian Archers, 52; Frolov, Skifÿ v Afinakh, 135-142; Alekseev, Khronografiya Evropeiskoi, 165-168. 
(para mayor interés, griegas) con la intención de representar ese papel de manera fácilmente reconocible (peltastas, etc.).

Del mismo modo, aun si el común de la población no tenía los conocimientos militares mínimos para diferenciar un peltasta de un hoplita (y al menos todos los varones debían tenerla sin duda), a lo largo de la historia las artes han contado con suficientes convencionalismos, recursos en el lenguaje simbólico y códigos figurativos lo suficientemente comprensibles para cualquier tipo de espectador como para destacar a unos personajes sobre otros de diversas maneras y no solo a través de su vestimenta (posición central, focalización de la acción a través de miradas o movimientos, etc.). Por ello no parece que se pueda defender adecuadamente la elección de los escitas por este motivo.

De hecho, podemos recordar fácilmente las escenas en que Teseo aparece acompañado de su fiel amigo Pirítoo, sin que sea necesario vestir a este con atuendo escita para ejemplificar fácilmente su papel secundario, el cual viene marcado por la propia escena a la que se alude y que es conocida por el espectador, ni siquiera se añaden los nombres de los actores para facilitar su reconocimiento, pues no es necesario. Del mismo modo, existen representaciones de héroes griegos con este tipo de atuendo escítico ( $y$ no hoplita o el usual para que este fuera reconocido a través de la piel de león, etc.). Sucede en un quílice, sobre el que se ha especulado indicando que su combate con los sátiros para proteger a Hera suponía la asunción por su parte de una condición "policial» que le asociaría a los esclavos escitas que actuaban de ese modo en Atenas (Fig. $2)^{75}$, aunque esta explicación no parece sólida ${ }^{76}$.

75. Frolov, Skif̈̈ v Afinakh, 142.

76. Del mismo modo que opina Ivantchik (Scythian' Archers, 197, 206) ya que la existencia de dichos "policías» fue posterior a la de elaboración del vaso (480 a. C.), aunque indica que su lucha al lado de Hermes colocaría a Heracles en una posición secundaria frente al dios que explicaría el abandono de su vestimenta característica por la de los escitas, no resulta más convincente por los ejemplos ya señalados de Pirítoo. 


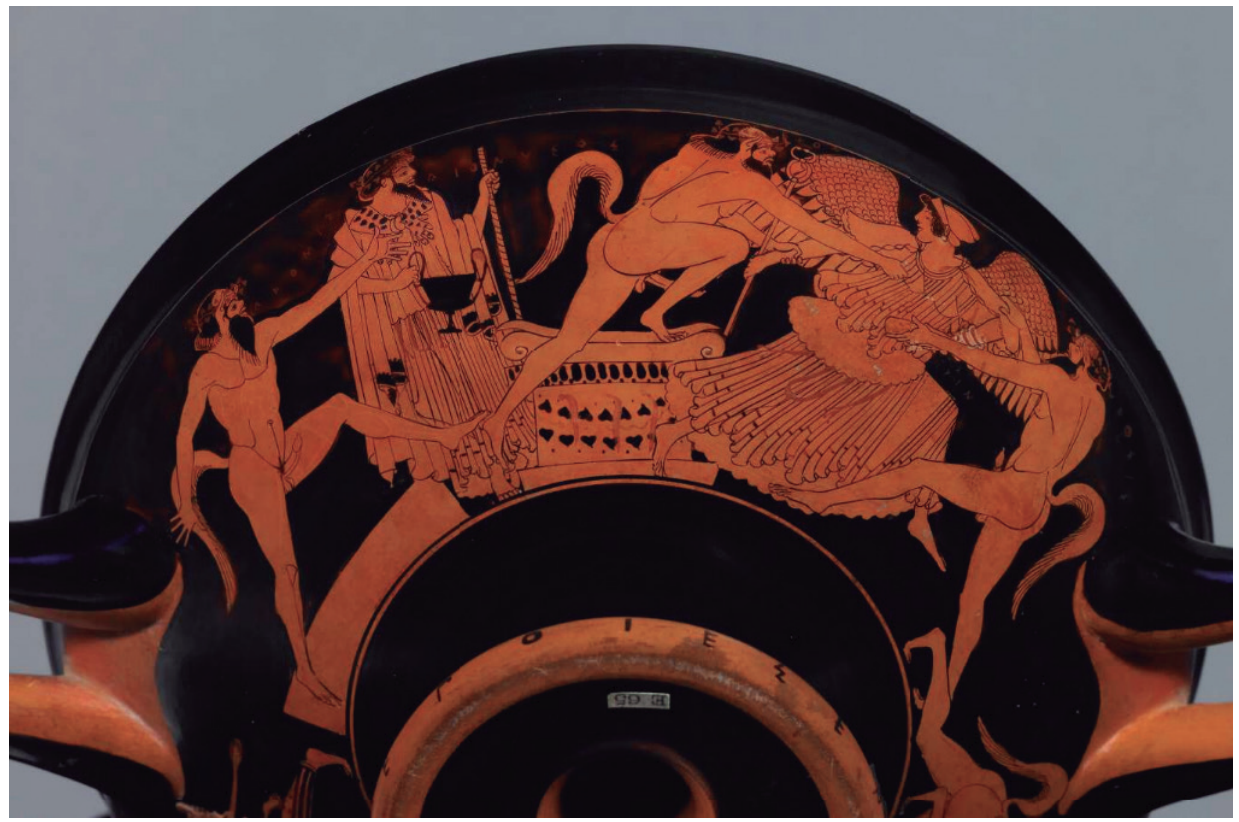

Fig. 2. Quílice de figuras rojas atribuido al Pintor de Brygos. Brit. Mus. Inv. 1873,0820.376. Vase E65.

Alekseev, A. Yu. Khronografiya Evropeiskoi Skifii VII - IV vekov do n.é. St. Petersburg, 2003.

Azarpay, Guitty. Urartian art and artifacts. Los Angeles: University of California Press, 1968.

Blok, Josine. The Early Amazons. Modern and Ancient Perspectives on a Persistent Myth. Religions in the Graeco-Roman World. Leiden: Brill, 1995.

Bothmer, Dietrich. Amazons in Greek art. Oxford: Clarendon Press, 1957.

Braund, D. "Scythian Archers, Athenian Democracy and a Fragmentary Inscription from Erythrae». En Antichnÿi mir $i$ Vizantiya. A special volume in bonour of the 70th birthday of V.I. Kadeyev (Kharkov), editado por V. F. Meshcheryakov, V. F. (ed.), 48-56, 1997.

Burney, C. A. "A First Season of Excavations at the Urartian Citadel of Kayahdere». Anatolian Studies 16 (1966): 55-112. 
Diakonoff, Igor. «The Cimmerians». En Monumentum Georg Morgenstierne I, editado por G. Lazard, 103-140. Leiden, 1981.

Duncan, A. M. "Bede, Iona and the Picts». En The Writing of History in the Middle Ages, editado por R. H. C. Davis y J. M. Wallace-Hadrill. Oxford, 1981.

Encinas Moral, A. L. Etnogénesis y evolución de la sociedad escita. Madrid: ALEM, 1999.

Frolov, É. D. "Skifÿ v Afinakh». VDI n. ${ }^{\circ} 1$ (1998): 135-142.

Gaydukevich, V. F. y S. I. Kaposhina. "K voprosu o mestnykh elementakh v kulture antichnykh gorodov severnogo Prichernomoria». SA. T. XV. S. (1951): 162-187.

Ghirshman, Roman y Thérèse Sonneville-David. Les Cimmériens et leurs Amazones: le manuscrit R.G. Paris: ADPF, 1983.

Grákov, Boris Nikolaevič. Die Skythen. Berlin: D. Wiss, 1971.

Harmatta, János. Studies on the bistory of the Sarmatians. Budapest: Pázmány Péter Tudományegyet. Görög Filol. Intézet, 1950.

Henning, Richard. "Neue Betrachtungen zur Geographie Homers». Geograph. Zeitschr. 32 (1926): 290-296.

Henning, Richard. «Die westlichen und nördlíchen Kultureinflüsse auf die antike Mittelmeerwelt». Klío 25 (1932): 1-21.

Ivantchik, Askold. "La légende "grecque» sur l'origine des Scythes (Hérodote 4.8-10)». En Origines gentium (Ausonius - Publications, Études 7), editado por V. Fromentin y S. Gotteland, 207-220. Bordeaux, 2001.

Ivantchik, Askold. "Le dêmos et la polis des Cimmériens dans l'Odyssée (XI, 14): le contenu de l'image épique». Collection de l'Institut des Sciences et Techniques de l'Antiquité (2005), 83-98.

Ivantchik, Askold. "Scythian' Archers on Archaic Attic Vases: Problems of Interpretation". Ancient Civilizations from Scythia to Siberia 12(3-4), (2006): 197-271.

Ivantchik, Askold. "Sinope et les Cimmériens». Ancient Civilizations from Scythia to Siberia 16 (2010): 65-72.

Jacobson, Esther. The art of the Scythians: the interpenetration of cultures at the edge of the Hellenic world. New York: E. J. Brill, 1995.

Kirchhoff, Adolf. Die Homerische Odyssee 2. Hildesheim: Olms Verlag, 1879.

Kristensen, Anne. Who were the Cimmerians, and where did they come from? Sargon 11, the Cimmerians, and Rusa l. Copenhagen: Munksgaard, 1988.

Latyshev, V. V. Izvestiya dreunikh pisateley o Skifii i kavkaze. San Petersburg: Farn, 1992. 
Lebedynsky, Iaroslav. Les Cimmériens, Les premiers nómades des steppes européennes IXe-VIIe siécles av. J.-C. Paris: Errance, 2004.

Lebedynsky, Iaroslav. De L'epee scythe au sabre mongol. Les armes blandes des nómades de la steppe. IXe siècle avant J.-C. - XIXe siècle après J.-C. Paris: Errance, 2008.

Lissarrague, François. L'autre guerrier. Archers, peltastes, cavaliers dans l'imagerie attique. Paris: Rome, 1990.

Mayor, Adrienne. The Amazons: Lives and Legends of Warrior Women across the Ancient World. Princeton: Princeton University Press, 2014.

Merrills, Andrew. History and Geography in Late Antiquity. Cambridge University Press, 2005.

Mohen, Jean-Pierre y Gosudarstvennyı̆ Ėrmitazh. Avant les Scythes: préhistoire de l'art en U.R.S.S. Paris: Éditions de la Réunion des musées nationaux, 1979.

Mongait, Alexander. Archaeology in the U.S.S.R. Baltimore: Penguin Books, 1961.

Parzinger, Hermann. Die Skythen. Wissen: C. H. Beck, 2016.

Piotrovskiy, B. Vanskoye tsarstvo (The Urartian kingdom). Moscow: Vostochnaya literatura, 1959.

Pisani, V. "Griechische Miszellen, 4: Kimmerier - Kimbroi». En Beiträge zur Ethnolinguistik. Gedenkschrift zum 100, editado por F. Hestermann. Jena: Friedrich-Schiller-Universitat, 1980.

Porada, Edith. The Art of Ancient Iran: Pre-Islamic Cultures. New York, 1965.

Prusek, J. Chinese statelets and the Northern barbarians in the period 1400-300 BC. Dordrecht: Reidel, 1971.

Rostowzew, Michael. Skythien und der Bosporus. Stuttgart: Steiner, 1993.

Salvini, Mirjo. Geschichte und Kultur der Uratiier. Darmstadt, 1995.

Sauter, Hermann. Studiem zum kimmerierproblem. R. Habelt, 2000.

Sánchez Sanz, Arturo. Ars Amazónica. Estudio de fuentes y análisis comparativo. Tesis doctoral presentada en la Universidad Complutense de Madrid, 2019.

Schiltz, Véronique. Les Scythes. Paris: Gallimard, 1984.

Schramm, Gottfried. Nordpontische Ströme. Namenphilologische Zuga n̈ge zur Fru hizeit des europa ïschen Ostens. Gottingen: Vandenhoeck Ruprecht, 1973.

Skrzhinskaya, M. V. "Geroi kimmeriiskikh i skifskikh legend v grecheskoi poézii i vazovoi zhivopisi VII-VI vv. do n.é». VDI 4 (1986): 84-94.

Unal, Vuslat. «Zwei Graber eurasischer Reiternomaden im nordlichen Zentralanatolien». BAVA 4 (1982): 65-81. 
Ustinova, Yulia. The supreme gods of the Bosporan Kingdom: Celestial Aphrodite and the Most High God. Leiden: Brill, 1999.

Waterman, Leroy. Royal Correspondence of the Assyrian Empire. Part I. Ann Harbor: University of Michigan Press, 1972.

Wilamowitz-Moellendorff, Ulrich. Homerische Untersuchungcn = Philologiscite Untersudtungen 7. Berlin. 1884.

Wilamowitz-Moellendorff, Ulrich. Diellias und Homer. Berlin, 1916. 